\title{
Factors That Influence the Level of Staff Involvement in the Strategic Planning Process in Public Institutions
}

\author{
Nancy Wairimu ${ }^{1}$,Fridah Theuri ${ }^{2}$ \\ ${ }^{I}$ Student, School of Human Resource DevelopmentJomo Kenyatta University of Agriculture and Technology \\ kenya \\ ${ }^{2}$ Lecturer, School of Human Resource DevelopmentJomo Kenyatta University of Agriculture and Technology \\ kenya
}

\begin{abstract}
The study set to establish the factors that influence the level of staff involvement in the strategic planning process in public institutions with specific reference to the department of immigration in Kenya. The research has explored literature on strategic planning in both public and private sector. The target population were senior, middle-level management and junior staff at the department of immigration. The study used a sample of 80, using the stratified sampling technique where the different strata are the different job groups. Questionnaires were used to collect data from the respondents and analyzed using the SPSS statistical tool. The research revealed that staff at the lower levels of the hierarchy are not aware of the strategic planning process or their roles in the planning process. The researcher provided a set of recommendations and suggested further areas of research.
\end{abstract}

Keywords: Strategic planning, staff awareness, staff roles and obligations, performance measurement

\section{Introduction}

Strategic planning is essential to every organization both profit making and non-profit making as it keeps the organization on track to reach the desired future. According to Johnson \& Scholes (2002, strategic planning is becoming more projects based and flexible. They further state that the strategic planning process ceases to be a vehicle for the top down development of intended strategy and more of a vehicle for coordination of strategy emerging from below.

Staff involvement is important in every organization as the staffs are directly involved in the implementation of strategies. Johnson \& Scholes (2002) states that people should be involved throughout the organization if planning is to avoid being removed from organizational reality. According to Henry (2008), strategy resulting from deliberations of corporate planning departments and senior management team may not be owned widely in the organization.

Johnson \&Scholes (2002) state that in strategic decision making, it is often helpful to engage employees directly in the strategy so that they can see what it means for them personally and how their role will change. Talking about strategy making and strategy implementation which forms part of the strategic planning process, they state that the process is often organized in the form of task forces which involve teams of people organized to work on a particular strategic issue over a defined period of time. Henry (2008) states that it is important during strategy formulation and implementation that everyone in the organization understands where it is going and how it will get there.

In Kenya, the public sector has embraced strategic planning with the objective of enhancing public service delivery. This follows the government realization that strategic planning embraces the notion of target setting at the ministerial, departmental, sectional and individual level.

According to the Economic Recovery Strategy for Wealth and Employment Creation (ERS) of 20032007 (GOK, 2003), the development of strategic plans for ministries and departments is considered a key element of the civil service reform strategy which would allow for proper utilization of resources, determination of appropriate staffing levels, staff appraisal and improved staff supervision.

Strategic plans in the public sector are anchored against the background of the Kenya Vision 2030 which is the country's economic blue print and long-term national planning strategy. It is also a key component of the results based management which is a tool that helps government ministries achieve desired results. They have also been adopted to help the government respond to the emerging challenges.

In the public sector, strategic planning is a participatory process that is lead by the ministry's management and sometimes a team of consultants. These have helped come up with ministry's mission, vision and the core values. Departments in each ministry further formulate their mission, vision, core values and formulate a strategic plan based on its key strategic issues.

The Government of Kenya has been undertaking a series of reforms aimed at enhancing quality, efficiency and transparency in service delivery by public sector institutions. Among the key reforms is the 
Results Based Management (RBM) generally and Performance Contracting (PC) in particular, which have strategic planning as the main point of reference. As indicated in the "General Guidance and Direction for Negotiating the 2007/08 Performance Contracts" the "Strategic Plan is the cornerstone for the design and development of a performance contract" in public sector institutions.

The mandate of the MIRP(now under the ministry of interior and coordination of national government as departments) was Kenyans and alien registration as well as migration management and facilitation. The ministry consisted of four departments; immigration, refugee affairs secretariat, national registration bureau and the civil registration department. The four departments have had their strategic plans based on their strategic issues and objectives which are also in line with the ministry's overall objective. The strategic plan for the MIRP is a 5 year plan in concurrence with vision 2030 and aims at greater efficiencies and delivery of services.

According to the Information Booklet on Performance Contracts in the Public Service (Directorate of Personnel Management, 2005) a strategic plan provides the framework for the design of a performance contract as it contains the vision, mission and objectives of the department or agency. Staff involvement in strategic planning is therefore paramount as staff are involved in setting their individual targets in the performance contracts. Performance of public servants therefore is measured through targets set out in their performance contracts which are in line with the overall ministerial strategic objectives and the departmental and sectional objectives.

For the MIRP, strategic planning is required not only for performance contracting purposes but also for ensuring the realization of its goals and objectives in the dynamic environment in which it operates (MIRP Strategic Plan, 2008-2012). According to the strategic plan, strategic planning will ensure, among other benefits that MIRP is able to provide services that meet the evolving needs of nationals and foreigners. It also ensures that all MIRP staff understand the pertinent strategic issues and are committed to the attainment of the set objectives. The strategic plan enables efficiency and effective resources deployment and helps key stakeholders understand and approve the strategic objectives and the rationale for decisions about resource allocation. Moreover, it helps

MIRP to sustain its ability to adapt and change to rapidly changing circumstances while continuing to carry out its core functions. MIRP strengthens its monitoring and evaluation systems (M\&E) in line with Government M\&E policy and ensures performance management systems are tuned to maximize effectiveness.

As indicated, staff involvement has been highlighted to be a key factor in the realization of the strategic plan. This research therefore strives to investigate the factors influencing the level of staff involvement in the strategic planning process in public institutions.

\section{Research objectives}

1. To determine the level of participation in formulation of the department's strategic plans.

2. To establish the roles and obligations of staff in the strategic planning process.

3. To find out whether and to what extent staff at different levels are aware of the strategic plan and the strategic planning process.

4. To investigate whether staff participation in the strategic planning process affects staff performance measurement as evaluated in the appraisal reports.

\section{Literature Review}

There are many authors who explain the process of strategic planning and the various stages that employees are involved in. Kotlers model lays out the different steps of strategic planning in which employees at various levels of the hierarchy are involved in.

a)

Figure 1 Kotler's strategic planning process model

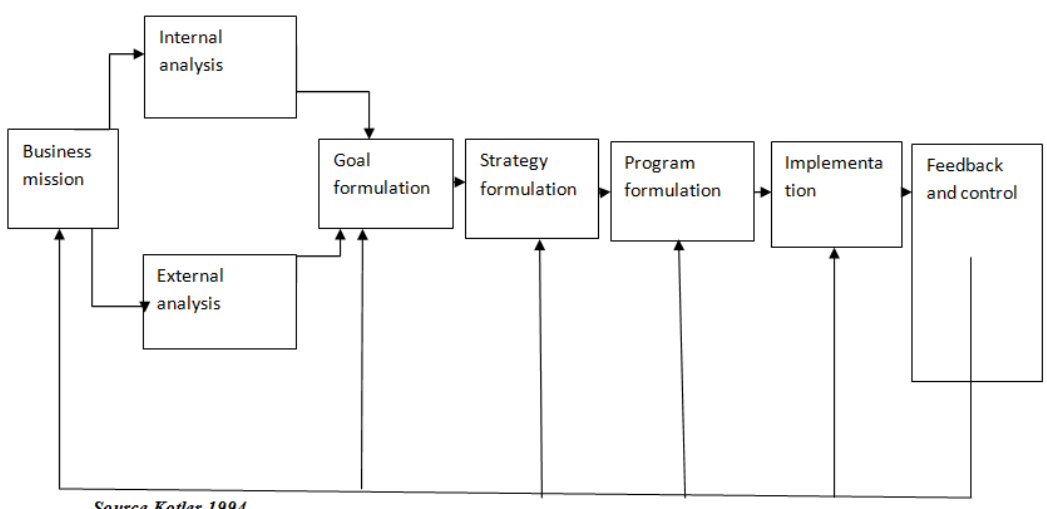


According to Kotler (1994) as explained in the above figure, organizations define their mission, swot analysis is done where both internal and external factors are analysed, goals formulated then strategies developed. The managers then formulate programs which are implemented and later feedback given.

Employees in various organizations are involved in one of the stages and in some all the stages depending on the position of the employee. Their involvement is determined by their rank, awareness or the roles assigned to them.

\section{Figure 2 Conceptual framework}

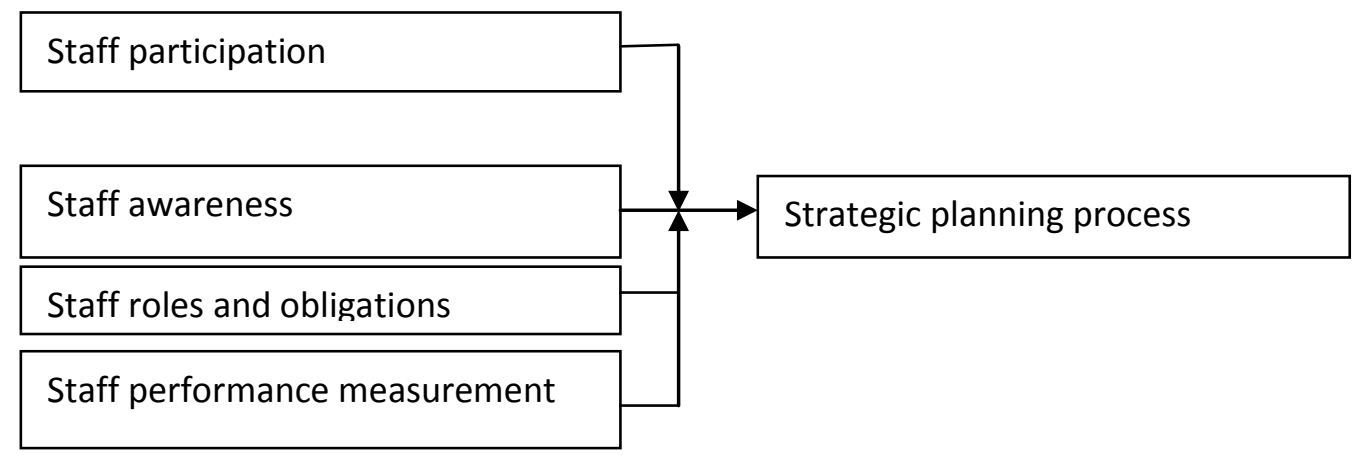

\section{Staff participation}

Strauss (2006) defines participation as a process that allows employees to exercise some control over their work and the conditions under which they work. It encourages employees to participate in the process of making decisions, which have a direct impact on work environment. He further states that substantial employee participation in management is vital for cross-functional integration and efficient working. Employee participation is therefore a method where, a large number of subordinates share a degree of decision-making power with their superiors.

The need for employees to be more involved in decisions that affect their work has been a center of argument in current management issues (Hales, 2000). Participation is about employees playing a greater role in the decision making process. It is an arrangement that ensure that employees are given the opportunity to influence management decisions and to contribute to the improvement of organizational performance (Armstrong, 2006).

Heracleous (2000) also finds that if middle management do not think the strategy is the right one, or do not feel that they have the requisite skills to implement it, then they are likely to sabotage its implementation. He refers to groups within the organization who will inevitably disagree with the strategy. These groups may sabotage strategy implementation by deliberate actions or inactions, if implementing the strategy may reduce their power and influence.

The degree of participation by non-managerial employees in decision making varies from one organization to another. Studies have however shown that employee participation is positively related to performance, satisfaction, and productivity of an employee (Pfeffer, 1994). The purposes of employee participation have been defined by Marchington et al. (1992) as expression of collective organization - to provide a countervailing source of power to management; contribution to management decision making - to seek improvements in work organization, quality and productivity; and demonstration of mutuality and cooperative relations - to achieve long term viability for the organization and its employees.

According to Harrison (1999), strategic planning starts with strategic objectives. Objectives indicate what management expect to accomplish while planning sets forth how, when, where and by whom objectives will be attained.

\section{Staff roles and obligations}

Steiner (1979) asserts that Strategic planning is a backbone support to strategic management. He further states that everyone recognizes that strategic and operational management are tightly linked. Strategic management provides guidance, direction and bound for operational management. He indicates that strategic planning is central to helping managers discharge their strategic management responsibilities

Strategic planning is a function and responsibility of all managers at all levels in an organization. It is obvious however that the planning responsibility of managers will vary significantly among types of organization and different organization levels (Steiner, 1979). Top management should expect middle-level managers to question strategic decisions (Wooldridge \& Floyd, 1990). Middle managers expect top management direction, but frequently feel that they are in a better position to start and evaluate alternative courses of action. 
Wooldridge \& Floyd (1992) classify middle management involvement in strategy into four types: championing alternatives, synthesizing information, facilitating adaptability and implementing deliberate strategy. The first two represent upward forms of involvement, while the last two are downward forms.

Strategic planning can help the people involved, the policy makers and key decision makers can be helped to fulfill their roles and responsibilities and participation in the process can improve their teamwork and expertise (Kim, 2002). According to Kim (2002) leaders, managers and planners need to engage in strategic planning carefully because the success will depend at least in part on how they tailor the process to their situations

Bryson (2004) states that some people or group must initiate the strategic planning process identify which persons, groups, units or organizations should be involved in the effort. In environmental scanning, both employees and board members should consider supplementing their informal effort with a somewhat formal external assessment. Bryson (2004) further asserts that strategic planning done by policy makers or line managers is most likely to be implemented. Insiders typically are the chief implementers of strategies so their ownership in the process and resultant decisions may be what is most crucial.

However, the responsibility for preparing a strategic plan can be delegated to a planner assigned to work with an organizations strategic planning team or the organization chief executive may choose to draft the plan. The support and commitment of key decision makers are vital if strategic planning in an organization is to succeed. According to Bryson (2004), the involvement of key decision makers outside the organization is usually crucial to the success of public and nonprofit programs when implementation will involve multiple partners and organizations.

\section{Staff awareness in strategic planning}

Thompson \&Martin (2005) defines strategic awareness as the understanding of managers within the organization about the strategies being followed by the organization and its competitors, how the effectiveness of these strategies might be improved and the need for suitability of opportunities for change. They further advices that managers must know the opportunities and threats facing them the organization must be able to synthesize all changes into a meaningful pattern and spread learning and best practice.

Mintzberg (1989) argues that organizations should have structures and managed to ensure formulators of strategy have information and that the implementers of strategies and changes have the appropriate degree of power to ensure that the desired changes are brought about.

Steiner (1979) for best results managers and staff in an organization must believe strategic planning is worth doing and must want to do it as well as they can. Also managers and employees of organization have interests that must be appraised and addressed in the planning process.

Simerson (2011) states that one of the most important benefits of any strategic planning effort is that it allows your organization to bring its "collective intelligence" together to apply to external forces, internal factors and state of current and emerging challenges and opportunities likely to impede or support the organizations attaining its vision and accomplishing its mission. Therefore, the employees involved in the process must be aware of their environment, the strategies, vision and mission for the success of the strategic plans.

Strategic decisions are formulated by senior-level managers of firm and then administratively imposed on lower-level management and non-management employees with little consideration of the resulting functional level perceptions (Nutt, 1987). If lower-level management and non-management personnel are not aware of the same information, or if information must pass through several layers in the organization, consensus regarding that information may never come about. Thus, the lack of shared knowledge with lower-level management and non-management employees creates a barrier to successful strategy implementation (Noble, 1999).

\section{Staff performance measurement}

Performance measurement is intended to produce objective, relevant information on program or organizational performance that can be used to strengthen management and inform decision making, achieve results and improve overall performance, and increase accountability (Poister, 2003). Poister states that performance measurement systems are used to support a variety of management functions, including the monitoring and reporting, strategic planning, budgeting and financial management, program management, program evaluation and performance management. He states that more proactive use of performance measures is in conjunction with strategic planning efforts. Emphasizing an organization's "fit" with its external environment; strategic planning approaches are designed to identify the most fundamental issues facing an organization in the long run and to develop strategies to resolve those issues effectively (Bryson, 1995).

Strategic plans usually define strategic goals and objectives, and it is essential, then, to define and monitor performance measures in order to track progress in implementing strategic initiatives and accomplishing strategic goals and objectives (Poister 2003). According to Poister, in some cases, desirable 
measures are actually defined first and then used to specify objectives and target levels to be achieved on these indicators of success.

Strategic management is concerned with deciding in advance what an organization will do in the future, that is planning; determining who will do it and how it will be done (resource management), and monitoring and enhancing ongoing activities and operations (Steiss, 1985). Vinzant and Vinzant (1996) also identified performance measures derived directly from strategic goals and objectives, and links between strategic plans and budgets, as critical elements of the strategic management process. More recently, Poister and Streib (1999) added performance management; providing direction and control over the work of managers and employees to ensure their efforts focused on achieving strategic goals and objectives

\section{Data Analysis And Presentation}

The response rate was $66.3 \%$ with 53 questionnaires out of the 80 administered returned.

Extent to which staff at different levels are aware of the strategic planning process

Table 3.Within how long have you been aware of the strategic plan?

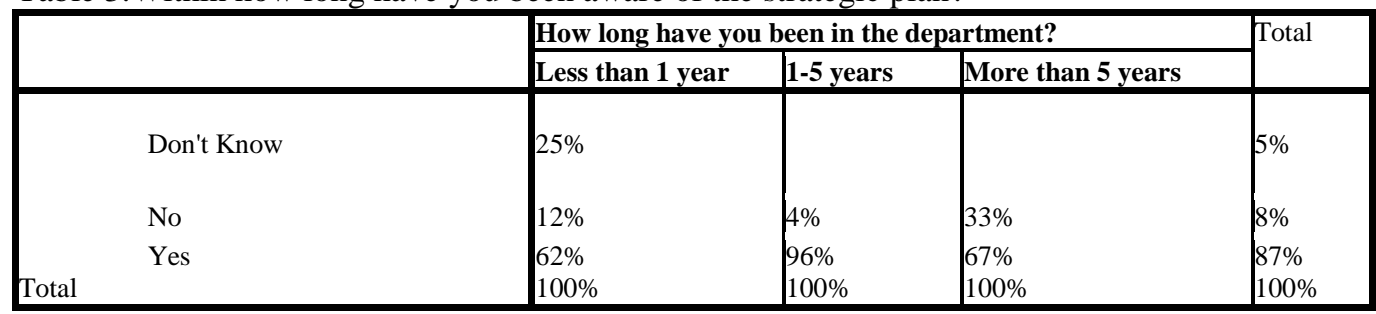

Table 3 shows the level of awareness of the strategic planning among staff in various sections. $25 \%$ of the respondents stated that they were not aware of the existence of a strategic plan and had been in the organization for less than a year; while $12 \%$ of the respondents with less a year in the organization stated that there existed no strategic plan; and among those with less than a year $62 \%$ of the respondents were aware of the strategic planning process.

For the respondents that had been in employment for one to five years; only $4 \%$ of then reported that they were not aware of the strategic planning process while $96 \%$ stated that they were fully aware of the process in the organization.

For respondents with more than five years in the organization $33 \%$ stated that they were not aware of the strategic planning process while $67 \%$ of them stated that they were aware of the strategic process.

From table 3.it is evident that the respondents that were between their second year and fifth year were well aware of the process of strategic planning hence shows that they were being involved in one way or the other by the organization hence understood. The fresh in the organization had lesser knowledge as regards to strategic planning while the elderly in the organization presented mixed results with a part of them stating that they were not aware of the process. This indicates that the organization has an obligation of ensuring that all the employees are well conversant with the process of strategic planning as it forms the backbone of the achieving of objectives in the entire organization.

From the data collected, the middle level managers felt the Ministry had made positive strides in terms of awareness regarding the strategic planning process. They said the Ministry has review meetings where information on strategic planning was shared. They added that employees were increasingly becoming accustomed with the strategic plan document. However, the respondents detailed that a lot still needs to be done so as to get information to the staff, especially those sitting at the lower end of the hierarchy.

\section{What stage of strategic planning process did you participate in?}

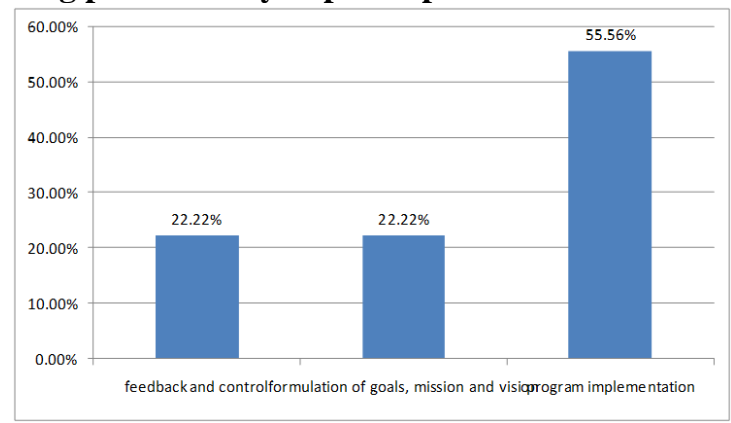

Figure 3 Participation in strategic planning process 
The researcher aimed at finding out from respondents whether strategic planning should be limited to certain structures after which the rest of the employees would then just be asked to implement or whether the process should entail everybody in the ministry, and to what extent.

From the figure 3 above it was evident that the respondents were involved in three stages of the strategic planning process that involved the feedback and control; formulation of goals, mission and vision; and the stage of strategy formulation. The study showed that $22.2 \%$ of the respondents were involved in the feedback and control stages, while $22.2 \%$ of the respondents were also involved in the formulation of goals, mission and vision; and 55.6\% stated that they were faced with strategic planning at the stage of program implementation.

All respondents felt that there was a need to encompass all staff members in the strategic planning process. Respondents felt that the employees at all levels of management need to be involved because they are the ones that will be expected to implement the plan. They indicated that it would be advantageous if all staff members were involved from the beginning of the process in order to understand the plan and for them to know what is expected from them. Another respondent added that staff members will take ownership if they are involved.

Figure 4 Participation of respondents in strategic planning process

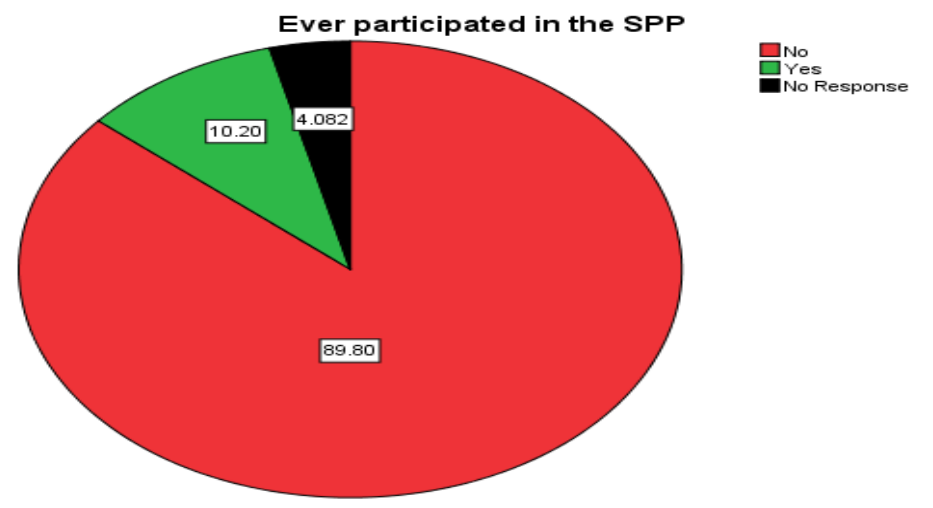

From the study, it is evident that senior managers felt staff members were well informed and involved. However, most of the respondents stated that there is a need to sensitize people, especially those in the lower ranks in the department. Regular briefing meetings were proposed by the respondents. Middle Managers also felt that in order for staff members to take ownership of the process, they need to be fully involved.

Relationship between the level of involvement and performance measurement

Table 4 Level of involvement and staff performance measurements

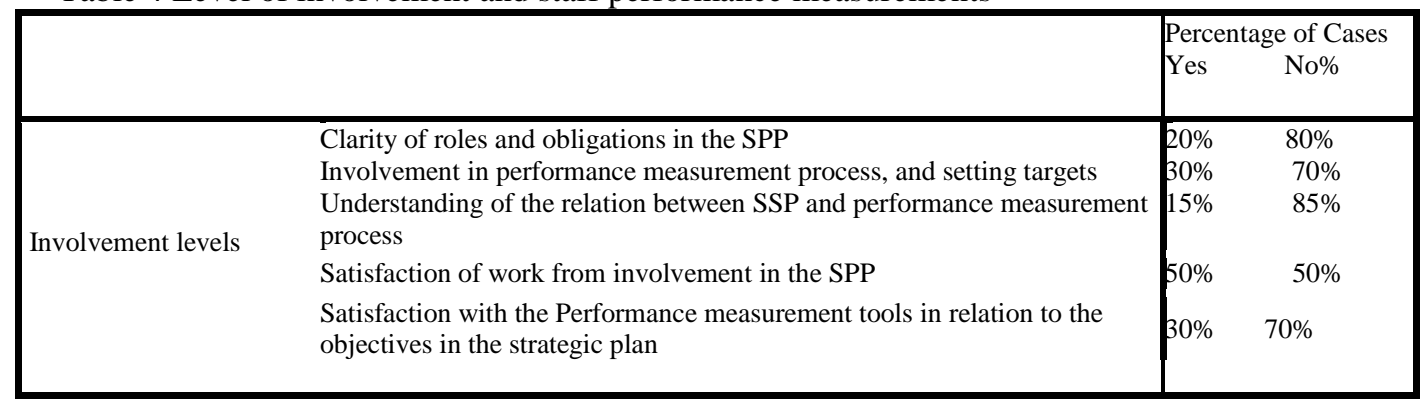

From the table 4 above, a response percentage of 20 of the respondents indicated that they had a clear understanding to their roles and obligations in the strategic planning process as compared to the other $80 \%$ of the respondents who did not clearly understand or had no knowledge of the roles with regards to strategic planning.

$15 \%$ of the respondents indicated that they understood the relationship between the strategic planning process and performance measurement. They indicated that they understood that the targets set in their performance appraisals were based on the strategic plan for the department. 85\% however did not understand the relationship between the objectives and the targets in the strategic plan and the individual targets in their performance contracts.

From the study, only $30 \%$ stated that they were involved in setting their own targets or were involved in performance measurement process. $70 \%$ were of the view that they were not involved in setting their targets or in setting a path to achieve the department's objectives. 
Additionally, a response percentage of 50 of the respondents stated that through their involvement in the strategic planning process they derived ultimate satisfaction in their work place. While $30 \%$ of the respondents through their involvement stated that they had been satisfied with the performance measurement tools that had been put in place so as to ensure that all the objectives that had been formulated with regards to the organization strategic plan were being met.

\section{Conclusion}

The first conclusion from the side of the researcher is that strategic plans are crucial documents for any organization both in the private and public sector. It serves as a guide and roadmap for an institution in pursuit of its stated objectives. However, for those responsible for the implementation of the programmes emanating from the planning process, it is one thing knowing what a strategic plan is and it another thing knowing the content of strategic plan. People should be able to understand the strategic plan and relate to it in terms of their own activities. It is further concluded that, less efforts is made by the department of immigration to sensitize junior staff members on the process of formulation and implementation of the strategic plan, especially employees at lower levels.

On the involvement of staff members on the strategic planning process, it is concluded that senior and middle level managers are fully involved in the process and contributed toward the formulation of the plan. However, it became evident that staff members at low ranking positions have less exposure to the process, hence could not provide more information about the process. This, according to the respondents, will discourage them from making positive contribution towards the attainment of the Ministry's or departments goals.

Moreover, when it comes to the morale and attitudes of employees towards the strategic planning process, the non-involvement of staff members, especially junior staff members has led to some staff members not taking ownership of the strategic planning process.

From this study, a conclusion is reached that, for any organization to succeed in the execution of its mandate, it needs to have a strategy that serves as a roadmap toward the realization of its objectives. This strategy must be effectively communicated and explained to all staff members in the organization.

\section{Journals}

\section{REFERENCES}

[1] Hales, (2000). Management and Empowerment Programs, Work, Employment and Society, Volume 14, Issue 3. 501-519

[2] Heracleous, L. (2000). The Role of Strategy Implementation in Organization Development. Organization Development Journal.Volume 18, Issue 3 75-86

[3] Marchington, Goodman, Wilkinson \&Ackers (1992). New Developments in Employee Involvement, Employment Department Research Paper Series, No. 2. London: HMSO.

[4] Noble, C. (1999) Building the strategy implementation network. Business Horizons, Volume 42,Issue 6 19-26

[5] Nutt, P. C. (1987). Identifying and appraising how managers install strategy. Strategic Management Journal volume 8, Issue 1

[6] Poister, T.H. \& Streib, G. (1999). Strategic management in the public sector; concepts, models and processes. Public Productivity and Management Review volume 22, Issue22.308-325

[7] Strauss (2006). Worker Participation: Some Under Considered Issues, Industrial Relations: A Journal of Economy and Society. Volume 45, Issue 4 778-803

[8] Vinzant, Douglas \& Janet, V., (1996). Strategy and Organizational Capacity: Finding a Fit. Public Productivity and Management Review, Volume 20, Issue 2 139-157

\section{Books}

[9] Armstrong, A Handbook of Human Resource Management Practice 10 ${ }^{\text {th }}$ edition( London: Kogan Page Limited,2006).

[10] Government of Kenya (2005). Directorate of personnel management booklet.

[11] Government of Kenya (2004). Public Service Commission of Kenya booklet.

[12] Government of Kenya(2003)Economic Recovery Strategy for Wealth and Employment Creation (ERS) of 2003-2007

[13] Harrison Michael,Organizational diagnosis and assessment; bridging theory and practice(California:Sage publications, 1999)

[14] Henry, A,Understanding Strategic Management(New York: Oxford,2008).

[15] Johnson,G. \& Scholes K Exploring Corporate Strategy $\left(6^{\text {th }}\right.$ Edition)Text and cases. (Harlow: Prentice Hall,2002)

[16] Kim W,Competitive strategy dynamics.(West Sussex: John Wiley \&sons Ltd,2002)

[17] Mintzberg, The Rise and Fall of Strategic Planning: Reconceiving the Roles for Planning, Plans, Planners.(New York: The free Press, 1994).

[18] Pfeffer, J,Competitive Advantage through People: Unleashing the Power of the Workforce(Boston: Harvard Business School Press, 1994).

[19] Poister, T.H,Measuring performance in public and nonprofit organization.(San Francisco: Jossey Bass,2003).

[20] Steiner, G. A., Strategic Planning: What Every Manager Must Know.(New York: Free Press,1979)

[21] Steiss AlanW,Strategic management and organizational decision making. (New York: Free press 1985)

[22] Simerson, B. K,Strategic Planning: A Practical Guide to Strategy Formulation and Execution. (California: Praeger, 2011)

[23] Thompson J. M, Strategic Management - Awareness and Change $5^{\text {th }}$ edition (New York: South Western,2005). 